\title{
Comparison of Estimated Glomerular Filtration Rate Mean Value of HARUS 15-30-60, HADI, and ASIAN Fomula Accuracy in Diabetes Mellitus Type 2
}

\author{
Sylvia Rachmayati, ${ }^{1}$ Ida Parwati, ${ }^{1}$ Abdul Hadi Martakusumah, ${ }^{2}$ Rachmat Soelaeman, ${ }^{2}$ \\ Nanan Sekarwana ${ }^{3}$

\begin{abstract}
${ }^{1}$ Department of Clinical Pathology, Faculty of Medicine Padjadjaran University-Dr. Hasan Sadikin General Hospital

${ }^{2}$ Department of Internal Medicine, Faculty of Medicine, Universitas Padjadjaran-Dr. Hasan Sadikin General Hospital
\end{abstract} \\ ${ }^{3}$ Department of Child Health, Faculty of Medicine, Universitas Padjadjaran-Dr. Hasan Sadikin General Hospital
}

\begin{tabular}{|c|c|}
\hline \multirow[t]{3}{*}{ Abstract } & $\begin{array}{l}\text { Objective: To compare the accuracy of HARUS } 15-30-60, \mathrm{HADI} \text {, and Asian } \\
\text { Formulas (Chinese-equation (Ch-E), Japanese-equation (Jp-E), and Thai- } \\
\text { equation (Th-E)) for estimated glomerular filtration rate (eGFR). }\end{array}$ \\
\hline & $\begin{array}{l}\text { Methods: The Kidney Dialysis Outcome Quality Initiative (KDOQI) has } \\
\text { published a guideline to measure renal function, which is based on glomerular } \\
\text { filtration rate (GFR). This procedure is complicated and expensive, therefore } \\
\text { an estimated GFR (eGFR) has been proposed. The modification of diet in renal } \\
\text { disease (MDRD) study prediction equation is the most frequently eGFR used. } \\
\text { This method still have a weakness in accuracy, so the chronic kidney disease } \\
\text { epidemiology collaboration (CKD-EPI) formula is developed. Since CKD-EPI } \\
\text { is not practical for daily use, the MDRD is published for Asian population } \\
\text { that includes Ch-E, Jp-E, and Th-E. In Indonesia, the MDRD formula has not } \\
\text { been validated using any gold standard, therefore } 2 \text { new formulas have been } \\
\text { developed, i.e. HARUS } 15-30-60 \text { and HADI formulas. In this study, we analyzed } \\
102 \text { medical records of Diabetes Mellitus Type } 2 \text { (DMT2) patients who visited } \\
\text { Dr. Hasan Sadikin General Hospital, Bandung during the period of } 2012 \text { to } \\
\text { 2013. We analyzed the data using HARUS } 15-30-60 \text {, HADI, Asian formulas, } \\
\text { and then compared them to CKD-EPI to see the accuracy. Statistical analysis } \\
\text { used was paired t-test in SPSS-17 program. }\end{array}$ \\
\hline & $\begin{array}{l}\text { Results: The accuracy of the different formulas are as follows: HADI } \\
(p=0.173) \text {, HARUS } 15-30-60(p=0.060) \text {, Ch-E }(p=0.001) \text {, Th- } E(p=0.000) \text {, and } \\
\text { Jp-E }(p=0.000) \text {. }\end{array}$ \\
\hline $\begin{array}{l}\text { Received: } \\
\text { June 17, } 2014\end{array}$ & $\begin{array}{l}\text { Conclusions: HADI is the most accurate formula, followed by HARUS Formula, } \\
\text { Ch-E, and Th-E and Jp-E, respectively. }\end{array}$ \\
\hline $\begin{array}{l}\text { Revised: } \\
\text { December 15, } 2014\end{array}$ & $\begin{array}{l}\text { Keywords: Chinese-equation, HADI and HARUS 15-30-60 formulas, } \\
\text { Japanese-equation, and Thai-equation }\end{array}$ \\
\hline $\begin{array}{l}\text { Accepted: } \\
\text { February 9, } 2015\end{array}$ & IJIHS. 2015;3(1):21-5 \\
\hline
\end{tabular}

\section{Introduction}

Chronic kidney disease (CKD) is one of the complications in diabetes mellitus type 2 (DMT2) which could lead to end-stage renal disease (ESRD). Therefore, it is required

\footnotetext{
Correspondence:

Sylvia Rachmayati, Department of Clinical Pathology, Faculty of Medicine, Universitas Padjadjaran-Dr. Hasan Sadikin General Hospital

Jl. Pasteur No. 38, Bandung, Indonesia e-mail: rachma210@gmail.com
}

to diminish the progression of CKD in the early stage. ${ }^{1,2}$ The most commonly used measurement of renal function in clinical medicine is the serum creatinine level. Currently, it is known that due to compensating tubular secretion of creatinine in CKD patients, serum creatinine level do not rise until the glomerular filtration rate is reduced about $50 \% .^{3-7}$ Therefore, Kidney Dialysis Outcome Quality Initiative (KDOQI) recommends that in assessing the level of kidney function, the serum creatinine concentration alone should 
not be used for this purpose. ${ }^{6}$ The best overall index of renal function is considered to be the glomerular filtration rate (GFR) and the gold standard for its assessment is the renal clearance of inulin or radiolabeled isotopes. Due to their complexities, both methods cannot be used routinely in daily practice. Formulas have been developed to calculated estimated GFR (eGFR). The most frequently used formula is the modification of diet in renal disease (MDRD) study prediction equation. Major limitations of this formula are imprecision and systematic underestimation of measured GFR (bias) at higher values. The MDRD formula was developed in 2009 and was validated as a new estimation equation based on the serum creatinine level, which would be as accurate as the MDRD Study equation at a GFR less than $60 \mathrm{~mL} / \mathrm{min}$ per $1.73 \mathrm{~m}^{2}$ and with more accurate result at a higher GFR. $^{3}$ The new formula is called the Chronic Kidney Disease Epidemiology Collaboration (CKD-EPI) formula. Chronic Kidney Disease Epidemiology Collaboration formula has two models based on serum creatinine, race, and gender. Though the eGFR calculation result of

Table 1 Chronic Kidney Disease Epidemiology Collaboration Equation ${ }^{10}$

\begin{tabular}{ccc}
\hline Gender & Creatinine Serum Level & Formula \\
\hline Female & $\leq 0.7 \mathrm{mg} / \mathrm{dL}(62 \mu \mathrm{mol} / \mathrm{L})$ & $\mathrm{GFR}=144 \times \frac{(\text { creatinine })^{-0.329} \times(0.993)^{\mathrm{age}}}{0.7}$ \\
& $>0.7 \mathrm{mg} / \mathrm{dL}(62 \mu \mathrm{mol} / \mathrm{L})$ & $\mathrm{GFR}=144 \times \frac{(\text { creatinine })^{-1.209} \times(0.993)^{\mathrm{age}}}{0.7}$ \\
Male & $\leq 0.9 \mathrm{mg} / \mathrm{dL}(80 \mu \mathrm{mol} / \mathrm{L})$ & $\mathrm{GFR}=141 \times \frac{(\text { creatinine })^{-0.411} \times(0.993)^{\mathrm{age}}}{0.9}$ \\
& $>0.9 \mathrm{mg} / \mathrm{dL}(80 \mu \mathrm{mol} / \mathrm{L})$ & $\mathrm{GFR}=141 \times \frac{(\text { creatinine })}{0.209} \times(0.993)^{\mathrm{age}}$ \\
\hline
\end{tabular}

CKD-EPI formula is more accurate than the MDRD formula, it is impractical for daily use. . $^{5-7}$

The MDRD formula needs to be adjusted if it is to be used for other than the white race. Therefore, the MDRD has been modified for the use in Asian population into the Chineseequation (Ch-E), Japanese-equation (Jp-E) and Thai-equation (Th-E). In Indonesia, the MDRD formula has been used widely despite the fact that it has not been validated. Martakusumah ${ }^{8}$ in 2012 has developed two new formulas, HARUS 15-30-60 and HADI, for estimating GFR in Indonesia. Since Kidney Disease Improving Global Outcomes (KDIGO) recommends the use of CKD-EPI formula to estimate GFR in clinical practice, this formula is used as the reference in this study. The accuracy of the Japan, HARUS 15-30-60, China, and Thailand formula in estimating GFR is then compared to that of CKD-EPI.

\section{Methods}

In this cross-sectional study, data collection was performed by collecting data on age, serum creatinine level, serum ureum level, and also albuminuria rate from the medical records of DMT2 patients who attended Dr. Hasan Sadikin General Hospital, Bandung during the period of 2012 to 2013. This study was conducted at the Department of Clinical Pathology of the Faculty of Medicine, Universitas Padjadjaran-Dr. Hasan Sadikin General Hospital, Bandung.

In this study, DMT2 was defined as a condition with diabetes history, anti-diabetes medication use, fasting blood glucose level $\geq 126 \mathrm{mg} / \mathrm{dL}$, or non fasting blood glucose level of $\geq 200 \mathrm{mg} / \mathrm{dL}$. Serum creatinine was analyzed using the enzymatic method, while serum ureum was analyzed using Cobas 6000 analyzer. Furthermore, albuminuria was analyzed using the dipstick method. The GFR was then estimated using CKD-EPI, Chinese equation, Japanese equation, and Thailand equation as well as HARUS 15-30-60 and HADI formula. The following formulas were used in this study:

HARUS 15-30-60 formula:

GFR $=15+30 /$ ureum level $+60 /$ serum creatinine level +0.1 (level of albuminuria by dipstick) - 0.2(age) ${ }^{9}$ 
HADI formula:

lon GFR $=4.996+0.163$ (albuminuria) 0.614(lon creatinine) - 0.314(lon ureum)

$\mathrm{GFR}=\operatorname{Exp}(\ln \mathrm{GFR})^{9}$
Japanese equation estimate of kidney function formula:

$194 \mathrm{x}$ serum creatinine-1.094 $\mathrm{x}$ age- 0.287 ( $\mathrm{x}$ 0.739 if female $)^{10}$

Table 2 Paired Samples Test

\begin{tabular}{lllll}
\hline & Mean & \multicolumn{2}{c}{ 95\% CI } & Sig (2-tailed) \\
\cline { 2 - 5 } & & Lower & Upper & \\
\hline Pair 1: Jp-E_CKD-EPI & -6.560 & -7.466 & -5.654 & 0.000 \\
Pair 2: Ch-E_CKD-EPI & 0.541 & 0.225 & 0.857 & 0.001 \\
Pair 3: HADI_CKD-EPI & 1.044 & -2.556 & 0.467 & 0.173 \\
Pair 4: HARUS15-30-60_ & 1.085 & -0.046 & 2.217 & 0.060 \\
CKD-EPI & & 3.511 & 4.965 & 0.000 \\
Pair 5: Th-E_CKD-EPI & 4.283 & & & \\
\hline
\end{tabular}

Thai equation estimate of kidney function formula:

$375,5 \mathrm{x}$ serum creatinine $1,234 \mathrm{x}$ age- 0.179 (x 0.712 if female) ${ }^{11}$

Chinese equation formula:

$175 \mathrm{x}$ serum creatinine-1.094 $\mathrm{x}$ age- 0.287 (x 0.742 if female) ${ }^{11,12}$

CKD-EPI formula:

Glomerular filtration prediction using CKD-EPI formula is divided into two major formulas i.e. formula for black race and white race or other. The formula of CKD-EPI for white race is usually used for other race. Indonesian people are not considered black or white. Therefore, in this study the formula for other race was used (Table 1).

All results were expressed in the form of mean \pm standard deviation (SD). The data to be analyzed were normally distributed based on Kolmogorov-Smirnov test. Hence, parametric tests were used in the statistical analyses. The prediction equations were evaluated based on recommendations in the National Kidney Foundation (NKF) KDOQI guidelines. Evaluations on bias, accuracy and significance were made. Paired samples t-test was used to compare the different formula to the reference standard. The mean difference (bias) between the paired observations is presented in SD (precision) and in p-values. The differences between the eGFR calculated using each of the different formulas (which include Japanese equation, Chinese equation, Thai equation and HARUS 15-30-60 formula) and the CKD-EPI as the reference standard in each patient allowed us to evaluate whether the equations under- or over-estimate the value of CKD-EPI (bias), which is the equation established by the KDOQI as the best criteria for comparing the accuracy of different equations in estimating GFR.

\section{Results}

During the study period, 102 medical records of patients hospitalized in Dr. Hasan Sadikin General Hospital with DMT2 diagnosis met the inclusion criteria with complete data of age, serum creatinine level, serum ureum level, and albuminuria rate. The equations of accuracy are listed (Table 2).

HADI was the most accurate formula, followed by HARUS Formula. Both formulas had a mean value that was similar to the reference value $(p>0.05)$. In the third position was Ch-E, followed by Th-E and Jp-E in the last place of accuracy with mean values that were significantly different from the reference value $(\mathrm{p}<0.05)$. 


\section{Discussion}

This study analyzed eGFR mean value accuracy of HADI and HARUS 15-30-60 formulas with DMT2 patients as the subjects. HADI and HARUS 15-30-60 formulas were developed by Martakusumah $^{8}$ in 2012 as a new formula to measure eGFR in Indonesia.

This study was the first study to analyze HARUS 15-30-60 and HADI formula accuracy, as well as the accuracy of the Ch-E, Jp-E, and Th-E in DMT2. The eGFR estimation using MDRD formula generally includes creatinine, gender, and age variables. HARUS 15-3060 formula also includes creatinine, ureum, urinary albumin, and age variables. HADI formula's components are similar to those of HARUS15-30-60, but with excluding the age variable and expressing the result in lon. The components of Ch-E, Jp-E, Th-E, and also the CKD-EPI formulas include the followings: serum creatinine, age, and gender. Each of the formula has a different constant, but used creatinine as their based variable and age as the other variable. Therefore, this study suggested that this condition leads to different results for each formula. The urinary albumin is also included in HADI and HARUS 15-30-60 as one of their variables in the equation. The author suggested that the addition of urinary albumin in eGFR formula results in a better accuracy value, due to the fact that the urinary albumin describes the function of glomerulus and tubulus. ${ }^{2,13-16}$ This study showed that eGFR from HADI and HARUS 15-30-60 formulas had better accuracy values for eGFR than other formulas after comparisons with CKD-EPI formula as the reference formula were made.

All variables of eGFR in this study that are directly related to the filtration process in the kidney are creatinine, ureum, and urinary albumin, which are the endogenous substances for kidney functional markers. Other variables such as age, gender, and race are indirectly related to the eGFR. Creatinine is produced by muscles; thus when there is a lack of muscles mass, creatinine concentration serum is low e.g. in elderly population. Age is an important factor because it affects the creatinine product and directly influences GFR. In elderly, the availability of functional nephrosis is reduced. Gender also gives influence because women have less muscle mass than men, leading to a less creatinine product in women. Studies in many countries have proven the influence of race towards eGFR. Ureum in serum is included in eGFR formula because it is an endogenous substance directly related to the filtration process in the kidney. However, this has limitationa because serum ureum is influenced by food intake and reabsorption in the intestines.

A previous study was performed in various hospitals in Bandung by Martakusumah ${ }^{8}$ by including pre-dialysis patients various etiologies of CKD as the subjects. The aim of the study ${ }^{8}$ was to assess the accuracy and precision of HARUS formula compared to Asian Formula, using the radio nuclear medicine as a gold standard. The study showed that the Asian Formula mean values were significantly different from HARUS formula mean values and the Chinese MDRD had the closest mean value of eGFR to HARUS Formula, which only had $-2,84 \mathrm{~mL} / \mathrm{min} / 1,73 \mathrm{~m}^{2}$ difference value compared to other Asian Formula. ${ }^{8}$ This study differs in the subject included compare to Martakusumah ${ }^{8}$. This study analyzed the mean value of eGFR from DMT2 patient.

HADI is the most accurate formula for calculating eGFR, followed by HARUS formula. In the third position was $\mathrm{Ch}-\mathrm{E}$, and followed by Th-E and Jp-E in the last place of accuracy.

\section{References}

1. Yee J. Diabetic kidney disease: chronic kidney disease and diabetes. Diabetes Spectrum. 2008;21(1):8-10.

2. Bucay CA, Viswanathan G. Urinary markers of glomerular injury in diabetic nephropaty. Int J Nephrol. 2012(2012):1-11.

3. Levey AS, Coresh J. Chronic kidney disease. Lancet. 2012;379(9811):165-180.

4. Collins AJ, Foley RN, Gilbertson DT, Chen SC. The state of chronic kidney disease, ESRD, and morbidity and mortality in the first year of

dialysis. Clin J Am Soc Nephrol. 2009;4(Suppl 1):S5-11.

5. US Renal Data System. USRDS 2013 annual data report: atlas of chronic kidney disease and of end stage renal disease in the United States. Bethesda: National Institutes of Health, National Institute of Diabetes and Digestive and Kidney Diseases. 2013;1:1-150.

6. US Renal Data System. USRDS 2013 annual data report: atlas of chronic kidney disease and end stage renal disease in the United 
States. Bethesda: National Institutes of Health, National Institute of Diabetes and Digestive and Kidney Diseases. 2013;2:151-478.

7. Kidney Disease: Improving Global Outcomes (KDIGO). KDIGO clinical practice guideline for yhe evaluation and management of chronic kidney disease. Kidney Int Supp. 2012;3(1):18163.

8. Martakusumah A. Formula baru untuk mengestimasi laju filtrasi glomerulus pada penderita penyakit ginjal kronik pra dialisis [dissertation]. Bandung: Universitas Padjadjaran; 2012.

9. Kitiyakara C, Yamwong S, Vathesatogkit P, Chittamma A, Cheepudomwit S. The impact of different GFR estimating equations on the prevalence of CKD and risk groups in a Southeast Asian cohort using the new KDIGO guidelines. BMC Nephrol. 2012;13(1):1-9.

10. Imai E, Yoshinari Y, Makino H. Japan Association of Chronic Kidney Disease Initiatives (J-CKDI). JMAJ. 2011;54(6):403-5.

11. Praditpornsilpa K, Townamchai N, Chaiwatanarat T, Tiranathanagul K, Katawatin P, Susantitaphong P, et al. The need for robust validation for MDRD-based glomerular filtration rate estimation in various CKD populations. Nephrol Dial Transplant. 2011;26(9):2780-5.

12. Ma YC, Zuo L, Chen JH, Luo Q, Yu XQ, Li Y, et al. Modified glomerular filtration rate estimating equation for chinese patients with chronic kidney disease. J Am Soc Nephrol. 2006(17):2937-44.

13. Birn H, Christensen EI. Renal albumin absorption in physiology and pathology. Kidney Int. 2006;69(3):440-9.

14. Haraldsson B, Nyström J, Deen WM. Properties of the glomerular barrier and mechanism of proteinuria. Physiol Rev. 2008;88(2):451-87.

15. Satchell SC, Tooke JE. What is the mechanism of microalbuminuria in diabetes: a role for glomerular endothelium? Diabetologia. 2008;51(5):714-25.

16. Araki S, Haneda M, Koya D, Isshiki K, Kume S, Sugimoto T, et al. Association between urinay type iv collagen level and deterioration of renal function in type 2 diabetic patients without overt proteinuria. Diabetes Care. 2010;33(8):1805-10. 